(C)2009 IEEE. Personal use of this material is permitted. However, permission to reprint/republish this material for advertising or promotional purposes or for creating new collective works for resale or redistribution to servers or lists, or to reuse any copyrighted component of this work in other works must be obtained from the IEEE. 


\title{
Derivation of A Mathematical Structure for Market-Based Transmission Augmentation in Oligopoly Electricity Markets using Multilevel Programming
}

\author{
M. R. Hesamzadeh, Graduate Student Member, IEEE, D. Biggar, ACCC Consultant, \\ N. Hosseinzadeh, Member, IEEE and P. J. Wolfs, Senior Member, IEEE
}

\begin{abstract}
In this paper, we derive and evaluate a new mathematical structure for market-based augmentation of the transmission system. The closed-form mathematical structure can capture both the efficiency benefit and competition benefit of the transmission capacity. The Nash solution concept is employed to model the price-quantity game among GenCos. The multiple Nash equilibria of the game are located through a characterisation of the problem in terms of minima of the $\mathcal{R}$ function. The worst Nash equilibrium is used in the mechanism of transmission augmentation. The worst Nash equilibrium is defined as the one which maximises the social cost, total generation cost + total value of lost load. Thorough analysis of a simple three-node network is presented to clearly highlight the mechanism of the derived mathematical structure from different perspectives.
\end{abstract}

Index Terms-Transmission Augmentation, Oligopoly Electricity Market, Multilevel Programming

\section{INTRODUCTION}

$\mathrm{T}$ HIS paper provides a closed-form mathematical structure for market-based transmission augmentation in restructured electricity markets. Optimal expansion of the network is critical for efficient operation of the electricity markets through providing a fair competitive environment for market players. Higher than optimal congestion, higher than optimal power losses, lower than optimal reliability, imperfect competition in generation, and inefficient electricity market are the five main costs of insufficient transmission capacity, [1]. The mechanisms of transmission augmentation are currently ill-defined and almost all of them do not have a closed-form mathematical structure. The references [1], and [2] set up a framework for transmission planning based on the marginal value of transmission capacity. Despite of having a closed-form formulation, the mechanism can not capture the competition effect of transmission capacity. Reference [3] employs the same mathematical structure of [1] but using the congestion cost and congestion revenue as the driving signals for the need of network expansion. The proper level of congestion for a transmission network and the competition benefit of transmission capacity are two main shortcomings of the proposed framework. References [4] and [5] suggest a new algorithm for transmission augmentation based on the congestion cost and the flatness of price profile. The spread of electricity price over transmission network is not an exact measure of competitiveness and consequently it is not suitable for identifying system bottlenecks, [3]. The whole process of planning does not have a closed-form mathematical formulation and it is unsuccessful in modelling the interaction between the availability of transmission capacity and market power in generation. Reference [6] suggests two heuristic procedures for transmission augmentation. The authors use unconstrained oligopoly equilibrium for the set of producers' bids while the bids from the demand side are assumed as known from the analysis of the existing market data. Clearly, unconstrained oligopoly equilibrium can not reflect the reality of the electricity market.

On the other hand, reference [12] showed numerically that transmission expansion reduces generators' market power. Reference [7] has examined empirically the bidding behaviour of generators in England and Wales, including the impact of transmission constraints. Accordingly, reference [7] reports that in England and Wales generators protected by transmission constraints bid significantly higher than those without this status. Obviously, generating companies' strategic bidding is as an ultimate outcome of market power. This could result in a transfer of transmission rents from Market Management Company, MMC, or owner of the transmission assets to the Generating Company, GenCos. Using a simplified version of the power network in California, [13] has quantified the impact of local market power and transmission capacity. References [8] and [9] show that generators benefit from a reduction in transmission capacity. Using a stylized version of the North America transmission system, reference [14] highlights the effect of transmission capacity on encouraging competition among Generating Companies, GenCos. Unlike the efficiency effect of transmission capacity, the competition effect has not received enough attention in transmission planning methodologies.

TEAM methodology introduced by the California ISO [15] can be acknowledged as a good model for market-based transmission augmentation. However, it has two drawbacks. Firstly, the strategic bidding of GenCos has been estimated through a tailor-made and empirical methodology which limits its application. Secondly, the whole framework does not have 
an integrated mathematical framework.

In National Electricity Market, NEM, Australia, the regulatory test introduced by the Australian Competition and Consumer Competition, ACCC, is used as the transmission augmentation criterion for the transmission network service providers over different states. In February 2003, the ACCC published a discussion report on a review of the regulatory test. Whether or not competition Benefit of transmission capacity should be included in the regulatory test has been one of the important themes of the ACCC discussion report. Commissioned by the ACCC in June 2003, reference [16] has carried out a review and analysis on the issues arising from the practical implementation of the approaches to the measurement of competition benefits proposed by interested parties in response to the Commission's discussion paper. Reference [17] has proposed a heuristic approach for evaluating competition benefits of transmission capacity. The integration of competition benefit in regulatory test is still under developed and demands more research. Using the multilevel programming, this paper derives a closed-form mathematical structure for transmission augmentation. The solution concept of Nash equilibrium has been employed for the analysis of the future condition of the electricity market. Multiple Nash equilibria has been formulated as the zeros of a nonnegative function and the worst case Nash equilibrium is selected as the equilibrium point of the electricity market. Finally, the whole mechanism of planning is modelled in an integrated mathematical framework. While some parts of the derived mathematical structure is not unique to this paper, this paper is however the first one which designs these mechanisms in an integrated structure. Also, to the authors best knowledge, the derived structure of transmission augmentation has not been used before in the electricity market literature. The mathematical derivation of the problem is detailed in section II. Section III applies the mechanisms on a simple three node network. Finally, concluding remarks will close this paper.

\section{BUILDING THE MATHEMATICAL STRUCTURE FOR TRANSMISSION AUGMENTATION}

In the light of the electricity market in Australia, the Transmission Network Service Provider, TNSP, is assumed as a regulated monopoly business. The TNSP is required to efficiently plan the transmission network and provide a fair competitive environment for market participants. The Generating Companies, GenCos, are assumed as independent business bodies competing for having the highest share from the electricity market. Finally, the Market Management Company, MMC, as the manger and operator of the electricity market which is completely independent from TNSP and GenCos. Now we consider a decentralised noncooperative decision system in which one leader and several followers of equal status are involved. We assume that the leader and followers may have their own decision variables and objective functions. The leader can only influence the reaction of followers through his own decision variables, while the followers have full authority to decide how to optimise their objective functions with respect to leader's decision as well as other followers ' decision. Multilevel programming [10] is used as a powerful tool for deriving the transmission augmentation structure. Subsection A deals with the application of the Nash concept for modelling of competition among GenCos. The formulation of Nash concept as an optimisation problem will enable the structure to locate all Nash equilibria of the game. Subsequently, subsection B models the TNSP as the leader of the game. Multiple Nash points are tackled through the selection of the worst Nash equilibrium in terms of total cost of generation and total value of lost load.

A. Nash equilibria of the simultaneous move game on price quantity among GenCos as zeros of $\mathcal{R}$ function

The cost function of a generating company can be modelled as a quadratic function of the form (1).

$C\left(g_{i}\right)=b_{i}+c_{i} g_{i}+a_{i} g_{i}^{2} \quad$ where $0 \leq g_{i} \leq g_{i}^{\max }$

In (1), $a_{i}\left(\frac{\$}{M W^{2}}\right), b_{i}(\$)$, and $c_{i}\left(\frac{\$}{M W}\right)$ are the cost function coeffiecinets. Technically, the coefficient $a_{i}$ is close to zero and the quadratic cost function can be approximated by a linear function of the form (2).

$C\left(g_{i}\right)=b_{i}+c_{i} g_{i} \quad$ where $0 \leq g_{i} \leq g_{i}^{\max }$

In (2), $g_{i}^{\max }$ is the total generation capacity, and $g_{i}$ is the generation level of GenCo $i$ assigned by the MMC. Each GenCo offers a price-quantity pair $\left(c_{i}^{\prime}, g_{i}^{\max }\right)$ to the MMC to participate in the market. The marginal cost of a GenCo and its bidding strategy are shown on figure 1 .

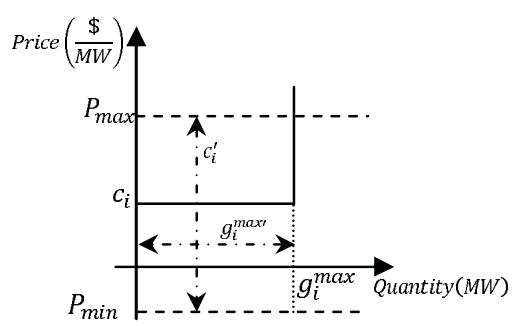

Fig. 1, The marginal cost curve and the biding strategy of a GenCo

The $P_{\min }(\$)$ and $P_{\max }(\$)$ are the minimum and maximum limits on price offer of a GenCo. Theses limits are usually set by the electricity market regulator. The competition on price, the competition on quantity and the competition on both price and quantity are economic structures established to model GenCos in an electricity market. This paper uses the pricequantity game to model GenCos in an electricity market. Given the bidding strategies of other GenCo and TNSP 's planning schedule revealed, each GenCo can find its optimal strategy using the bilevel programming problem in (3).

$$
\begin{array}{r}
\operatorname{Max}_{c_{i}^{\prime}, g_{i}^{\max }} \llbracket v_{i} g_{i}-C\left(g_{i}\right) \rrbracket \\
\text { s.t. } \\
P_{\min } \leq c_{i}^{\prime} \leq P_{\max } \\
o \leq g_{i}^{\max } \leq g_{i}^{\max }
\end{array}
$$




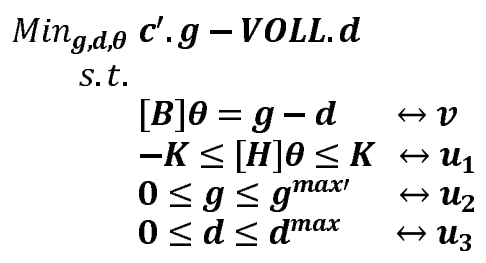

In (3), $[\boldsymbol{B}]$ and $[\boldsymbol{H}]$ are $N_{b} \times\left(N_{b}-1\right)$ and $N_{l} \times\left(N_{b}-1\right)$ matrices where the column related to the slack bus is omitted, $N_{b}$ and $N_{l}$ are the total number of buses and total number of lines in the system. $\boldsymbol{\theta}$ is the vector of bus angles, $\boldsymbol{g}$ and $\boldsymbol{d}$ are the generation level of committed generators and the served demand of retailers. In $(3),(\boldsymbol{u}, \boldsymbol{v})$ is the Lagrange multipliers of the associated constraints. The vector $\boldsymbol{v}$ is the price of energy at different network connection points. Capacity of the transmission system has been modelled through vector $\boldsymbol{K}$.

Using the Karush-Kuhn-Tucker optimality conditions, the (3) can be generalised as in (4).

$$
\underset{\mathbf{z} \in \boldsymbol{Z}}{\operatorname{Max}_{\boldsymbol{y}_{i} \in \boldsymbol{Y}_{\boldsymbol{i}}}} f_{i}\left(\boldsymbol{x}, \boldsymbol{y}_{\boldsymbol{i}}, \boldsymbol{y}_{-\boldsymbol{i}}, \mathbf{z}\right)
$$

Where in (4), $\boldsymbol{x}=\boldsymbol{K}$ is the TNSP decision vector, $\boldsymbol{y}_{\boldsymbol{i}}=$ $\left(c_{i}^{\prime}, g_{i}^{\text {max }}\right)$ is the action vector of the $\mathrm{i}^{\text {th }} \mathrm{GenCO}$, and $\boldsymbol{y}_{-\boldsymbol{i}}=$ $\left(\boldsymbol{y}_{1}, \ldots, \boldsymbol{y}_{\boldsymbol{i}-1}, \boldsymbol{y}_{\boldsymbol{i}+1}, \ldots, \boldsymbol{y}_{\boldsymbol{m}}\right)$ with $m$ as the total number of GenCos. $\boldsymbol{z}=(\boldsymbol{g}, \boldsymbol{d}, \boldsymbol{\theta}, \boldsymbol{u}, \boldsymbol{v})$ and $\mathbf{z}$ vector is constrained by the set of $\mathbf{Z} . \mathbf{Z}$ is the set defined by the constraints of the inner optimisation problem in (3).

Since all GenCos are of equal status, they must reveal their strategies simultaneously. Hence, for all GenCos a popular solution concept is the Nash equilibrium.

The Nash equilibrium problem can be formulated as the problem of finding the zeros of function $\mathcal{R}$ which is defined in (5).

Definition: Let $\mathrm{Y}$ be a nonempty set which defines the strategy space of all GenCos participating in the electricity market. The function $\mathcal{R}(\mathbf{y}): \mathbf{Y} \rightarrow \mathbb{R}^{+}$is defined as (5):

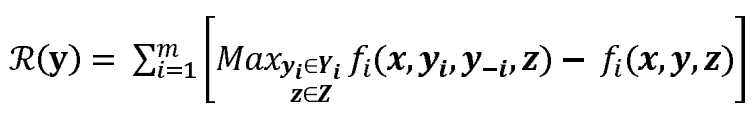

The following theorem can be derived consequently;

Theorem: The function $\mathcal{R}(\mathbf{y}): \mathbf{Y} \rightarrow \mathbb{R}^{+}$is real and nonnegative on Y. Also, Nash equilibria are the zeros of $\mathcal{R}$.

Proof: The theorem can be proved by the classical definition of Nash equilibrium.

Having (5) as the alternative formulation of Nash equilibria, the mathematical framework of the competition among GenCos can be built as in (6).

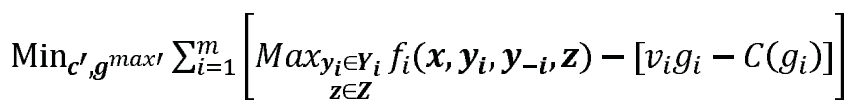

$$
\begin{aligned}
& \text { s.t. } \\
& \boldsymbol{P}_{\text {min }} \leq \boldsymbol{c}^{\prime} \leq \boldsymbol{P}_{\text {max }} \\
& o \leq \boldsymbol{g}^{\max } \leq \boldsymbol{g}^{\max } \\
& \operatorname{Min}_{\boldsymbol{g}, \boldsymbol{d}, \boldsymbol{\theta}} \boldsymbol{c}^{\prime} \cdot \boldsymbol{g}-\boldsymbol{V O L L} \cdot \boldsymbol{d} \\
& \text { s.t. } \\
& {[B] \theta=g-d \leftrightarrow v} \\
& -K \leq[H] \theta \leq K \leftrightarrow u_{1} \\
& 0 \leq \boldsymbol{g} \leq \boldsymbol{g}^{\max \prime} \leftrightarrow \boldsymbol{u}_{2} \\
& 0 \leq d \leq d^{\max } \leftrightarrow \boldsymbol{u}_{3}
\end{aligned}
$$

If an array $\boldsymbol{y}=\left(\boldsymbol{y}_{1}, \ldots, \boldsymbol{y}_{i}, \ldots, \boldsymbol{y}_{\boldsymbol{m}}\right)$ satisfies that $\mathcal{R}\left(\boldsymbol{y}_{1}, \ldots, \boldsymbol{y}_{\boldsymbol{i}}, \ldots, \boldsymbol{y}_{\boldsymbol{m}}\right)=0$, then $\mathbf{y}$ must be a solution of (6) and consequently a Nash equilibrium of the game. The set of all optimal solutions of (5) are the Nash equilibria of the pricequantity game among GenCos. If (5) does not have any optimal solution, there is no Nash equilibrium of GenCos in the given bilevel programming problem. Section B addresses the issue of multiple Nash equilibria and the TNSP objective function.

\section{B. The worst Nash equilibrium and the TNSP mathematical structure for augmentation}

The set of Nash equilibria of the price-quantity game can be found by solving the optimization problem formulated in (6).

Reference [17] uses an average method to deal with many Nash equilibria of the quantity game among GenCos. This method calculates the situation of the market under each each Nash equilibrium. Then after, the method takes an average for each of variables of interest in the process of transmission augmentation. In some cases the average of interested variable approaches zero and can not provide any valuable information to the process of transmission augmentation. Also, all different Nash equilibria are treated with the same weight which is not a true assumption.

This paper uses the worst Nash equilibrium in terms of total cost to the society for modelling of electricity market situation in the process of transmission augmentation. The worst Nash equilibrium is the one which has the highest social cost to the society. The social cost is the total cost of generation and total value of lost load. By doing this, firstly, the worst equilibrium of the market is used in transmission augmentation as a signal which is always available and secondly, all Nash equilibria are not treated with same weight. The mathematical formulation of the worst Nash equilibrium is formulated in (7).

$$
\operatorname{Max}_{\boldsymbol{c}^{\prime}, g^{\max }}[\boldsymbol{c} . \boldsymbol{g}-\boldsymbol{V O L L} . \boldsymbol{d}]
$$

In (7), c. $g-V O L L . d$ is the total cost to the society which must be computed over each of Nash equilibria of the GenCos' price-quantity game.

Suppose the TNSP has $m$ options of upgrade and $n$ options of expansion for the market-based augmentation of the high voltage transmission system on its given territory. For the $m$ options of upgrade, $\boldsymbol{k}_{l}^{u}, l=1, \ldots, m$ and for the $n$ options of expansion, $\boldsymbol{k}_{l}^{e}, l=1, \ldots, n$ are the vectors of maximum thermal capacity which can be built on the transmission corridors of upgrade and expansion, respectively. Vector $\mathrm{K}$ is 
defined as $\left(\boldsymbol{k}_{l}^{u}, \boldsymbol{k}_{l}^{e}\right)$. Similarly, $\boldsymbol{t} \boldsymbol{c}_{\boldsymbol{l}}^{\boldsymbol{u}} l=1, \ldots, m$ and $\boldsymbol{t} \boldsymbol{c}_{\boldsymbol{l}}^{\boldsymbol{e}}$ $l=1, \ldots, n$ are the vectors of the investment cost for the transmission upgrade and expansion projects, respectively. Figure 2 shows this situation.

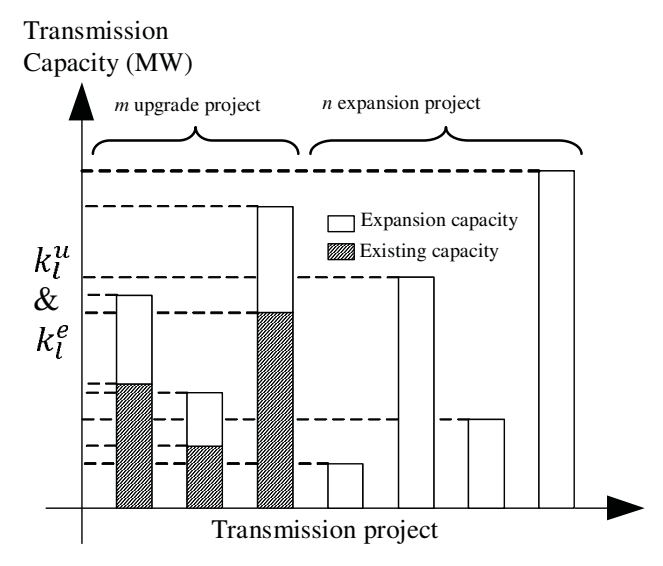

Fig.2, TNSP's transmission projects

Since TNSP pays the investment cost of upgrade or expansion, it is desirable to upgrade and/or expand the transmission system with the minimum cost. Mathematically, the TNSP's cost function can be formulated as (8).

$$
\begin{aligned}
& \operatorname{Min}_{\boldsymbol{k}^{u}, \boldsymbol{k}^{e}} \llbracket\left(\sum_{l=1}^{m} k_{l}^{u} t c_{l}^{u}+\sum_{l=m+1}^{m+n} k_{l}^{e} t c_{l}^{e}\right)+\operatorname{Max}_{\boldsymbol{c}^{\prime}, \boldsymbol{g}^{\max }}[\boldsymbol{c} \cdot \boldsymbol{g}- \\
& \boldsymbol{V} \boldsymbol{O} \boldsymbol{L L} \boldsymbol{d} \boldsymbol{d}]
\end{aligned}
$$

s.t.

$$
\begin{aligned}
& 0 \leq k_{l}^{u} \leq k_{l}^{u, \max } l=1, \ldots, m \\
& 0 \leq k_{l}^{e} \leq k_{l}^{e, \max } l=m+1, \ldots, m+n \\
& \operatorname{Min}_{\boldsymbol{c}^{\prime}, \boldsymbol{g}^{\max }} \sum_{i=1}^{m}\left[\begin{array}{c}
\operatorname{Max}_{\boldsymbol{y}_{\boldsymbol{i}} \in \boldsymbol{Y}_{\boldsymbol{i}}} f_{i}\left(\boldsymbol{x}, \boldsymbol{y}_{\boldsymbol{i}}, \boldsymbol{y}_{-\boldsymbol{i}}, \mathbf{z}\right)-\left[v_{i} g_{i}-\right.
\end{array}\right.
\end{aligned}
$$

Cgi]

$$
\begin{aligned}
& \text { s.t. } \\
& \boldsymbol{P}_{\min } \leq \boldsymbol{c}^{\prime} \leq \boldsymbol{P}_{\max } \\
& o \leq \boldsymbol{g}^{\text {max }} \leq \boldsymbol{g}^{\text {max }} \\
& \operatorname{Min}_{\boldsymbol{g}, \boldsymbol{d}, \boldsymbol{\theta}} \boldsymbol{c}^{\prime} \cdot g-V O L L . d \\
& \text { s.t. } \\
& \begin{array}{ll}
{[B] \theta=g-d} & \leftrightarrow v \\
-K \leq[H] \theta \leq K & \leftrightarrow u_{1} \\
0 \leq \boldsymbol{g} \leq \boldsymbol{g}^{\text {max }} & \leftrightarrow \boldsymbol{u}_{2} \\
\mathbf{0} \leq \boldsymbol{d} \leq \boldsymbol{d}^{\text {max }} & \leftrightarrow \boldsymbol{u}_{3}
\end{array}
\end{aligned}
$$

$k_{l}^{u, \max }$ and $k_{l}^{e, \max }$ are the maximum values for the $k_{l}^{u}$ and $k_{l}^{e}$ as the TNSP's design parameters.

Optimisation set (8) can be used as a closed-form mathematical structure for transmission augmentation. In (8), the TNSP moves first and designs the future transmission system. Based on the planning schedule, the Nash equilibria of the price-quantity game are calculated. In next step, the worst Nash equilibrium is found and the generation costs and total value of lost load of the worst Nash equilibrium are added to the TNSP 's planning schedule cost as the total cost of expansion. For demonstration purposes, section III applies the proposed mechanism of transmission planning to a simple three-node network without engaging with the numerical solution of the derived mathematical structure.

\section{APPLICATION OF THE PROPOSED MECHANISIM ON A SIMPLE THREE-NODE SYSTEM}

The proposed mathematical structure in (8) is applied on a simple three-node system. The single line diagram of the example system is as shown in figure 3. GenCos and retailers offers and bids are also shown in figure 3.

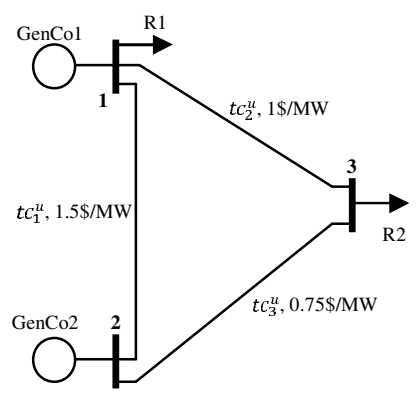

Fig. 3, The single line diagram of the three-node example system

Transmission lines $L 1, L 2$, and $L 3$ connect buses 1,2 , and3. The marginal transmission investments on these lines are 1.5, 1 , and $0.75 \$ / \mathrm{MW}$.

There are two competing generators labelled as GenCo1 and GenCo5, and two competing retailers labelled as R1 and R2 in the 3-bus example system. The TNSP is responsible for the market-based augmentation of the system. The information of the generators, retailers, and transmission network are shown in tables I, II, and III respectively. The upgrade or expansion projects for the existing transmission system are collected in table IV.

TABLE I GENERATORS 'DATA
\begin{tabular}{|c|c|c|}
\hline Generator & $g^{\text {max }}(\mathrm{MW})$ & $c(\$ / \mathrm{MW})$ \\
\hline GenCo1 & 200 & 30 \\
\hline GenCo2 & 200 & 20 \\
\hline
\end{tabular}

TABLE II RETAILERS 'DATA
\begin{tabular}{|c|c|c|}
\hline Retailer & $d^{\text {max }}(\mathrm{MW})$ & $\operatorname{VOLL}(\$ / \mathrm{MW})$ \\
\hline R1 & 150 & 10,000 \\
\hline R2 & 200 & 10,000 \\
\hline
\end{tabular}

TABLE III TRANSMISSION NETWORK DATA

\begin{tabular}{|c|c|c|c|c|}
\hline Line\# & From & To & Reactance(p.u.) & Limit(MW) \\
\hline 1 & B2 & B1 & 0.2 & 20 \\
\hline 2 & B2 & B3 & 0.2 & 40 \\
\hline 3 & B1 & B3 & 0.2 & 30 \\
\hline
\end{tabular}

TABLE IVTRANSMISSION NETWORK UPGRADE DATA

\begin{tabular}{|c|c|c|c|c|}
\hline Line\# & From & To & $\begin{array}{c}\text { Max } \\
\text { Capacity } \\
(\mathrm{MW})\end{array}$ & $\begin{array}{c}\text { Marginal } \\
\text { Investment } \\
\text { cost(\$/MW) }\end{array}$ \\
\hline 1 & B2 & B1 & 40 & 1.5 \\
\hline 2 & B2 & B3 & 40 & 0.75 \\
\hline 3 & B1 & B3 & 40 & 1.0 \\
\hline
\end{tabular}


For each GenCo, the $c_{i}^{\prime}, g_{i}^{\max }$ in the price-quantity pair $\left(c_{i}^{\prime}, g_{i}^{\max }\right)$ offered to the MMC have been approximated by a set of discrete variables. The $c_{i}^{\prime}$ can be varied from true marginal cost to 10 times of marginal cost in steps of 1 and $g_{i}^{\text {max }}$ can be selected from $25 \%$ of true generation capacity to total generation capacity in steps of $8.33 \%$. The strategy plane of GenCo $i$ is shown in figure 4.

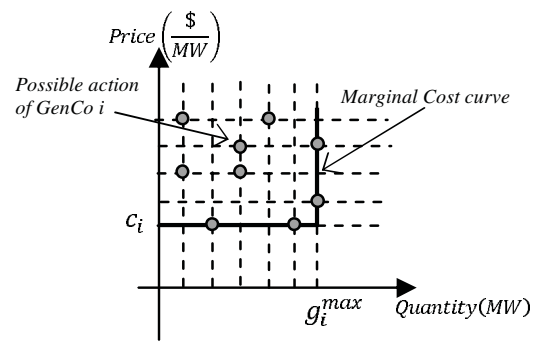

Fig. 4, The strategy plane of GenCo i

The bidding strategy of GenCo 1 and GenCo 2 considering the existing transmission system are shown on figures 5 and 6 .

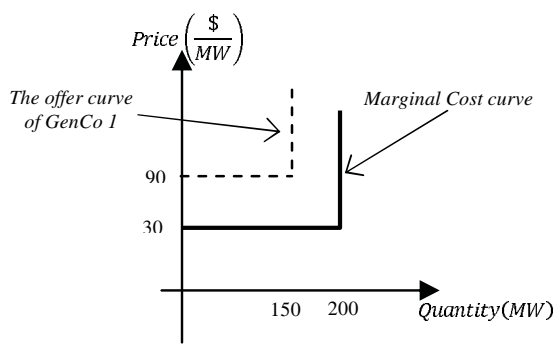

Fig. 5, Marginal cost and the strategy of GenCo 1 considering the existing transmission system

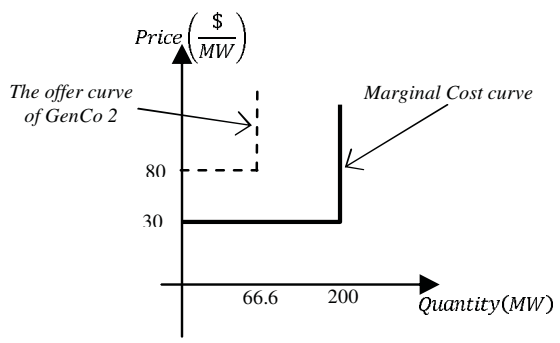

Fig. 6, Marginal cost and the strategy of GenCo 2 considering the existing transmission system

Regarding the GenCo 1, it offers a supply curve of 150MW at 90 \$/MW. The GenCo 2 offers a similar supply curve of 66.6MW at 80 \$/MW. Both GenCos enjoy from bidding a price above marginal cost and withholding their generation capacity. This strategic behaviour is the immediate result of insufficient transmission capacity.

Applying the proposed methodology formulated in (8), for each transmission augmentation schedule, the TNSP calculates all Nash equilibria of the price-quantity game between GenCo 1 and GenCo 2. Among the Nash equilibria set, the equilibrium which maximises the total cost to the society in trems of total generation dispatch cost and the total value of lost load are selected. The worst Nash equilibrium is used for electricity market studies in the horizon year of the planning. The summation of the transmission investment cost and the social cost calculated for the worst Nash equilibrium are the objective function of the TNSP for that specific transmission planning schedule. It is clear that the TNSP will choose the transmission augmentation plan with the minimum cost.

The TNSP has seven different planning schedules as tabulated in table $\mathrm{V}$.

TABLE V THE TNSP TRANSMISSION PLANNING OPTIONS ALONG WITH ASSOCIATED COST

\begin{tabular}{|c|c|c|c|}
\hline $\begin{array}{c}\text { TNSP } \\
\text { planning } \\
\text { schedule }\end{array}$ & $\begin{array}{c}\text { No. of } \\
\text { Nash } \\
\text { equilibria }\end{array}$ & $\begin{array}{c}\operatorname{Max}_{\boldsymbol{c}^{\prime}, g^{\max }}[\boldsymbol{c} \cdot \boldsymbol{g}- \\
\boldsymbol{V} \boldsymbol{O L L} \boldsymbol{d}](\$)\end{array}$ & $\begin{array}{c}\text { TNSP total cost } \\
\text { (\$) }\end{array}$ \\
\hline $\begin{array}{l}\text { Original } \\
\text { Network }\end{array}$ & 19 & $1,418,300$ & $1,418,300$ \\
\hline L1 & 30 & $1,686,333$ & $1,686,393$ \\
\hline L2 & 46 & $1,443,500$ & $1,443,540$ \\
\hline L3 & 20 & $1,351,167$ & $1,351,197$ \\
\hline L1-L2 & 21 & $1,671,333$ & $1,671,433$ \\
\hline L1-L3 & 50 & $1,351,167$ & $1,351,257$ \\
\hline L2-L3 & 1 & 674,333 & 674,403 \\
\hline L1-L2-L3 & 31 & $1,030,167$ & $1,030,297$ \\
\hline
\end{tabular}

Based on the table V, the TNSP will approve the building of lines two and three in order to improve the electricity market performance. By doing this, the total cost has decreased dramatically from $\$ 1,418,300$ to 674,403 which corresponds to about $\% 52$ of decrease in the TNSP cost. The difference of total generation cost and total value of lost load before and after expansion corresponds to the efficiency and competition benefit of the transmission capacity. In our example, the efficiency and competition benefits of transmission capacity is about $\$ 1,418,300$ - $\$ 674,333=\$ 743967$.

The offer curves of GenCos 1 an 2 before and after transmission expansion are shown in figures 7 and 8 .

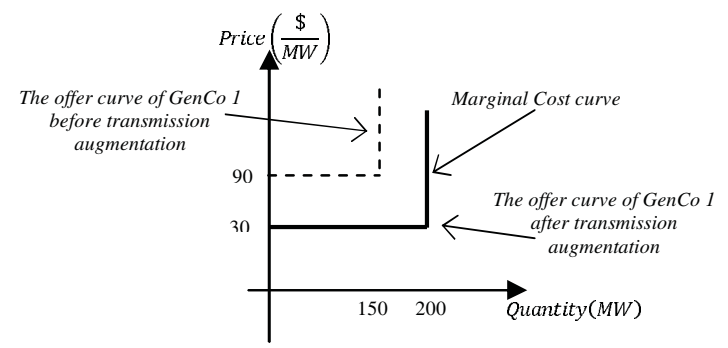

Fig. 7, Marginal cost and the strategy of GenCo 1 before and after transmission augmentation

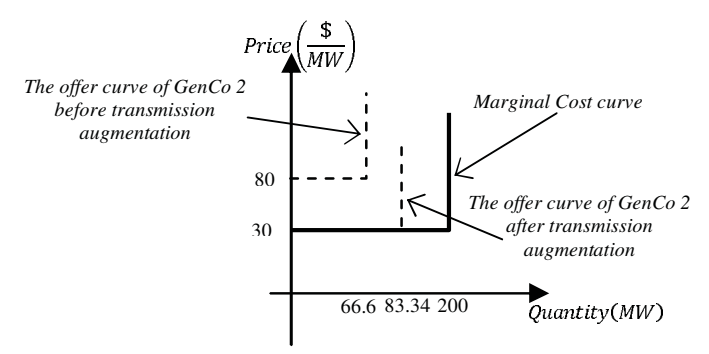

Fig. 8, Marginal cost and the strategy of GenCo 2 before and after transmission augmentation

As it is clear, after the approval of lines 2 and 3, the strategic 
behaviour of GenCo 1 and GenCo 2 are limited. The GenCo 1 offers its true marginal cost and its total generation capacity for participating in the energy market. Similarly, the GenCo 2 offers its true marginal cost with $83.34 \mathrm{MW}$ for participating the energy market. Although, the GenCo 2 still withholds some of its generation capacity, compared with its offered capacity before transmission augmentation, it offers more of its total generation capacity after the TNSP planning schedule. Although we did not engage with designing a numerical solution for the derived mathematical structure, but the application of the proposed mechanism on a simple three-node network shows that the designed mechanism can effectively capture both the efficiency benefit and competition benefit of the transmission capacity.

\section{CONCLUDING REMARKS}

In a fully competitive electricity market, each participant should bid at its true marginal cost with the true generation capacity to maximise its revenue. However, a practical electricity market is not perfectly competitive because of (1) the limited number of GenCos and retailers in the electricity market, (2) the limited transmission capacity, and (3) the imperfect information among market players. This paper has derived and evaluated a closed-form mathematical structure to capture both the competition benefit and the efficiency benefit of transmission capacity. The mathematical structure employs the Nash solution concept to model the price-quantity game among GenCos. To locate all Nash equilibria of the game, the Nash problem has been formulated as an optimisation problem. This formulation has been done by defining the socalled function which is a real nonnegative function. The function is strictly positive if the combined generators strategy is not a Nash equilibrium and equal to zero otherwise. Accordingly, the set of Nash equilibria is the set of zeros of the function. The worst Nash equilibrium has been selected in the process of the transmission augmentation. The worst Nash equilibrium is defined as the one which maximises the total cost to the society. The summation of total cost of generation and the total value of the lost load is used as the total cost to the society. Although we did not engage with the numerical solution of the proposed mathematical formulation, but the application of the mechanism on a simple three-node network is very satisfactory. The authors are currently developing an effective numerical solution for the derived mathematical structure to be applied on the eastern Australian transmission system.

\section{REFERENCES}

[1] T. O. Leautier, "Regulation of an electric power transmission company," The Energy Journal, vol. 21, No. 4, pp. 61-92, 2000.

[2] T. O. Leautier, "Transmission constraints and imperfect markets for power," Journal of Regulatory Economics 19:1 27-54, 2001.

[3] G. B. Shrestha, P.A.J. Fonseka, "Congestion deriven transmission expansion in competitive power markets," IEEE Trans. On Power Systems, Vol. 19, No. 3, Aug. 2004.

[4] M. O. Buygi, H. M. Shanechi, G. Balzer, M. Shahidehpour, N. Pariz, , "Network planning in unbundled power systems," IEEE Trans. On Power Systems, Vol. 21, No. 3, Aug. 2006.
[5] M. O. Buygi, H. M. Shanechi, G. Balzer, M. Shahidehpour, N. Pariz, , "Market-based transmission expansion planning," IEEE Trans. On Power Systems, Vol. 19, No. 4, Nov. 2004.

[6] W. Lu, E. Bompard, R. Napoli, X. Jiang, "Heuristic procedures for transmission planning in competitive electricity markets," Electric Power System Research, 2006.

[7] C. Wolfram, "Strategic bidding in a multi-unit auction: an emprical analysis of bids to supply electricity in England and Wales," The RAND Journal of Economics, 1998, Vol. 29, pp. 703-725.

[8] J. Bushnell, "Transmission rights and market power," The Electricity Journal, 1999, pp. 77-85.

[9] P. Joskow, and J. Tirole,"Transmission rights and market power on electric power network" The Rand Journal of Economics, 2000.

[10] B. Liu, "Stackelberg-Nash equilibrium for multilevel programming with multiple followers using genetic algorithm", Computers Math. Applic., Vol. 36, No. 7, pp. 79-89, 1998.

[11] M. Bazaar, C.M. Shetty, Nonlinear Programming, theory and applications, New York: John Wiley and Sons, 1979.

[12] P. Joskow, R. Schmalensee, " Market for power: an analysis of electric utility deregulation," MIT press 1983.

[13] S. Borenstein, J. Bushnell, S. Stoft, "The competitive effects of transmission capacity in a deregulated electricty industry" POWER Working paper PWP-040R, University of California Energy Institute, 1998

[14] T. O. Nasser, Imperfect markets for power: competition and residual regulation in the electricity industry, MIT press, 1997.

[15] The California ISO Transmission Economic Assessment Methodology.: California Independent System Operator, 2004.

[16] An analysis of competition benefits, Farrier Swier Counsulting, July 2003.

[17] Evaluating interconnection competition benefits, Frontier Economics, September 2004.

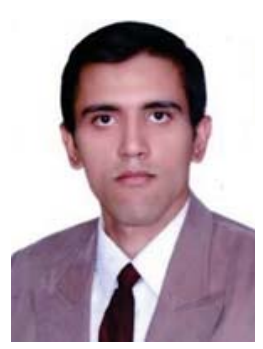

Mohammad R. Hesamzadeh (IEEE-GSM'08) is a $\mathrm{PhD}$ student with Swinburne University of Technology, Melbourne, Australia. His special fields of interest include high voltage transmission system planning and design, electricity market analysis, intelligent system applications in power systems, distribution and rural system studies, and high voltage engineering. $\mathrm{He}$ is a Graduate Student Member of IEEE, Vice Chair of IEEE, Queensland Power and Energy Chapter, and a Professional Engineer in Australia.

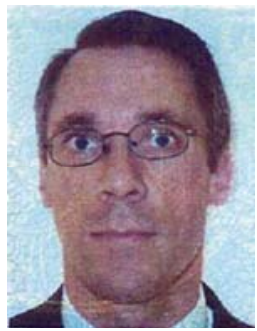

Darryl Biggar is an economist with the Australian Competition and Consumer Commission and the Australian Energy Regulator. He specializes in the economics of regulation, including issues such as the design of incentive mechanisms, foundations of regulation, and the design of electricity markets and water markets. He has a particular interest in electricity markets including issues of nodal and zonal pricing and the measurement and control of market power.

Prior to the ACCC, he worked for the OECD in Paris, the New Zealand government, and for University College, London. Biggar has a $\mathrm{PhD}$ in economics from Stanford University and an MA in Mathematics from Cambridge University. He is a native of New Zealand.

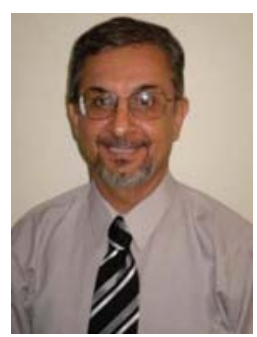

Nasser Hosseinzadeh (IEEE-M'86) is with Swinburne University of Technology, Melbourne, Australia. He graduated from Shiraz University, Iran, in 1986 with a B.Sc. degree in electrical and electronics engineering. He worked in a research centre for five years before starting his postgraduate studies. He received a M.Sc. degree from Iran University of Science and Technology in 1992 and a Ph.D. degree from Victoria University in Australia in 1998. His special fields of interest include power system analysis and planning, power system stability, intelligent system applications in engineering, distribution networks and rural energy supply. 


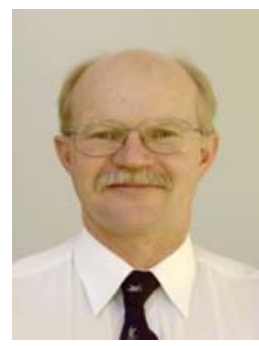

Peter J. Wolfs (IEEE-M'80-SM'99) was born in Rockhampton Australia in 1959. He graduated from the Capricornia Institute of Advanced Education in 1980 with a B.Eng. degree. He subsequently obtained the M.Eng. degree from the Philips International Institute in the Netherlands in 1981 and the Ph.D. degree at the University of Queensland in 1992. He is the Associate Dean (Research and Innovation) at the Faculty of Sciences, Engineering and Health at Central Queensland University. His special fields of interest include rural and renewable energy supply, solar and hybrid electric vehicles and intelligent systems applications in railways. Professor Wolfs is a Fellow of Engineers Australia, a Registered Professional Engineer in the State of Queensland and a member of the Railway Technical Society of Australia. 